\title{
INITIATING AND ASSESSING AN E-NUDGING MODEL FOR HIGHER EDUCATION IN SAUDI ARABIA
}

\author{
Salihah Alotaibi \\ Curtin University, WA, Australia
}

\begin{abstract}
Decisions related to education are complex and have long-term consequences. For higher education students, particularly first-year students, most of these decisions are made when students are young and with little academic experience; these decisions can potentially influence students' futures. This study aims to propose an e-nudging model for higher education that offers an early and low-cost support for universities to encourage better education decision-making for students in a digital environment (i.e. learning systems). The empirical study will be conducted in the Kingdom of Saudi Arabia (KSA) using a mixed-methods approach to assess the effectiveness of the proposed model derived from the literature review. Also, the study will examine the current factors (behavioral, cognitive, and environmental barriers) that influence the effectiveness of the e-nudging model. The research will enhance the understanding of behavioral and cognitive barriers in a digital environment, and how these influence students' decisions. The research will contribute by establishing a relationship between digital nudging, the field of Information Systems (IS) and Human Computer Interaction (HCI), in particular by assisting designers to understand student behaviors and guide users to make the most desirable choice. Lastly, the proposed e-nudging model will improve our understanding of the concept of digital nudging and its application in the learning and teaching field in the KSA and generally in the Gulf Cooperation Council (GCC) countries.
\end{abstract}

\section{KEYWORDS}

Digital Nudging, Educational Decision, Behavioral, Cognitive and Environmental Barriers, HCI

\section{INTRODUCTION}

Universities play a significant role in the human development process. Universities provide a high level of academic knowledge, educational skills, and learning experience to students, allowing them to make a more positive impact on society and the economy. Despite the importance of universities and their benefits, many students perform poorly or decide to drop out of university. In fact, the dropout rate from universities and colleges in Saudi Arabia is $30 \%$ (Sulphey \& Alkahtani, 2018). This high rate is attributed to several factors such as lack of student interest, poor attendance, and a social structure that has made the younger generation more immature and more dependent on family and society (Sulphey \& Alkahtani, 2018). In addition, some studies found that Saudi students are negatively influenced by scheduling issues (Khan, 2011) and lack time management skills resulting in overdue assignment submissions (Sulphey \& Alkahtani, 2018) These factors are more common among first-year students and have more detrimental consequences(Brock, 2010).

In the context of education decisions, students, face a series of complex decisions. Most of these decisions, which can potentially influence the students' futures, are made when students are young and have limited academic experience (Damgaard \& Nielsen, 2018). This complex situation may cause some students to postpone the completion of academic tasks, to make unwise or wrong decisions, miss key deadlines or lose confidence (Castleman \& Meyer, 2016). Furthermore, many studies indicate that adolescents are particularly likely to be impacted by self-control problems (Bettinger \& Slonim, 2007; Green, Fry, \& Myerson, 1994). In an online environment, sometimes the system's complexity or behavioral factors might affect the students' commitment, while interventions such as reminders may significantly increase student commitment to complete academic tasks and improve outcomes (Patterson, 2018). Therefore, understanding the cognitive, behavioral economics (Castleman \& Meyer, 2016) and environmental (Mirsch, Lehrer, \& Jung, 2017) 
barriers are essential when designing motivational interventions that reduce the detrimental impact of such barriers, because they secure the person's attention and possibly prevent unwise decision making.

This paper is organized as follows: section 2 provides a brief introduction to the education decision barriers including (behavioral economics, cognitive and environment). Section three (3) is the core of the research and presents the notion of nudging and proposed model. Section 4 describe of the research methodology. Finally, section 5 describe the research conclusion.

\section{LITERATURE REVIEW}

This section reviews the current literature relating to the factors that influence the effectiveness of the proposed e-nudging model for higher education in Saudi Arabia.

\subsection{Behavioral Economic Barriers}

The behavioral economic field is one that studies and describes economic decision-making. Behavioral economic insights become interesting topic to inform intervention design in education (Andor, Fels, Renz, \& Rzepka, 2018; Damgaard \& Nielsen, 2018; Hortal, 2019). One of the behavioral barriers is known as bounded rationality (Hortal, 2019; Patterson, 2018; Sulphey \& Alkahtani, 2018). Thaler and Sunstein (2008) state that irrational decisions are likely to occur in four situations. The first is when a person prefers to have immediate gratification and is prepared to deal with its cost in the future. The second situation is when no immediate feedback is given. Finally, there are situations which are unfamiliar, or which rarely occur. Unfortunately, in regard to education, many decisions are made by people who are young and therefore susceptible to making unwise or neon-optimal decisions (Damgaard \& Nielsen, 2018). In addition, some education decisions are difficult, complex, unfamiliar, and rare, because the university's environment is new. Students might not understand some academic practices, making it difficult for them to make decisions. Moreover, some situations may be unfamiliar and may rarely occur, so students cannot make decisions based on past experience. For example, choosing a college is usually a once-in-a-lifetime occurrence (Damgaard \& Nielsen, 2018; Thaler \& Sunstein, 2008). Another behavioral barrier that affects students' outcomes is lack of self-control. Thaler and Sunstein (2008) mention that, generally, a series of bad outcomes eventuate when people have self-control issues combined with mindless choices. During their study journey at university, students are required to make a sustained effort and stay motivated. Therefore, students need a gentle nudge to improve their outcomes and help them make better decisions.

\subsection{Cognitive Barriers}

Cognitive biases play an important role in the decision-making process. These biases occur because the human brain tends to simplify information processing by using different techniques such as heuristics. One important type of cognitive bias is attentional limitation. When student face a complex choice, they are more likely to pay attention to some information and (intentionally or unintentionally) ignoring other information, which leads to poor decisions. For instance, many researches have revealed that students have poor information about education policies such as administration, course withdraw, changing major policies, although the information is available (Damgaard \& Nielsen, 2018). Sometimes, the limited attention issue may cause students to forget to do tasks (Patterson, 2018). Moreover, optimism and over-confidence bias leads students to believe that their abilities are better than those of their peers (Damgaard \& Nielsen, 2018). Unrealistic optimism influences students' decisions which in turn impact on their academic performance. If the students face one or more of these cognitive biases, they are more likely to benefit from nudges.

\subsection{Environmental Barriers}

The environment and how information is presented strongly influence a person's choices and decisions. In a digital environment, people are more likely to make imperfect decisions. On screen, they make a quick and automated decision or choice as a result of the massive amount of information available on the Internet that 
make it difficult to process relevant details in order to make the best decision (Mirsch et al., 2017). Hovdhaugen and Aamodt (2009) found that dissatisfaction with the learning environment and problems related to academic achievements and motivation are reasons why students abandon higher education. Hence, some universities are now using electronic learning systems such as Blackboard and Angel/LMS Learning Management System (LMS) to enhance the education environment and make learning more convenient. These learning systems focus on providing efficient techniques to improve students' learning (Landry, Griffeth, \& Hartman, 2006; Talebian, Mohammadi, \& Rezvanfar, 2014). Nevertheless, many students found it hard to use, particularly those students who had less academic and computational experiences (Bradford, Porciello, Balkon, \& Backus, 2007). On other hand, Zhang, Almeroth, Knight, Bulger, and Mayer (2007) designed a learning system, similar to Moodle, that provides feedback and reminders to students via email. They found that the students become more interested in viewing course materials. Therefore, the creation of a learning environment that is easy to deal with and improves student motivation would influence students to make better decisions and improve their outcomes. To sum up, these barriers and limitations impede the learning process. They are predictable (Bradbury, McGimpsey, \& Santori, 2013; Thaler \& Sunstein, 2008), so decision-making can be framed in specific ways to nudge students to choose better in order to produce optimum outcomes.

\section{DIGITAL NUDGING}

Digital nudging is a concept that emerged in 2016. It transferred the nudge theory to the digital environment. Digital nudging "is the use of user-interface design elements to guide people's behavior in digital choice environments" (Weinmann, Schneider, \& vom Brocke, 2016). The authors argue that the concept of digital nudging is based on insights from behavioral economics. It deals with the user interface design elements to steer user behavior toward specific decision-making in a digital environment. In addition, there are several advantages of digital nudging: the implementation is easier, faster and cheaper; moreover, the Internet allows designers to tailor nudges for particular users, which makes them more effective (Mirsch et al., 2017). In addition, digital nudging can be easily generated and modified for a digital environment. Hence, the effectiveness of the nudging can be tested quickly by means of an online experiment (Schneider, Weinmann, \& vom Brocke, 2018).

\subsection{Digital Nudging Model}

This subsection reviews the current literature relating to nudging models. Currently there are five proposed models for nudging. One particular model for design nudging was proposed by (Ly, Mazar, Zhao, \& Soman, 2013). The authors proposed a general approach to nudge-development. They provided a sequential structure that makes the process more accessible. Weinmann et al. (2016) designed the first model for the digital nudging process, which comprise five phases for online decision environments. The second model proposed by Meske and Potthoff (2017), consists of a cyclical three-phase process for the design of digital nudges, called "digital nudging process model" (DINU). The third model proposed by Schneider et al. (2018), also developed a cyclical model to design digital nudges which contains four phases (identify the goals, understand the users, design the nudge, and test the nudge). The fourth model proposed by Bertheim (2018). In his model, he considered the ethics factor for the entire process, not just for design nudging phases .The last model modified the Schneider et al. (2018) model by considering timing as a critical factor for the success of digital nudges (Purohit \& Holzer, 2019).

However, after comparing these models, some of the processing steps and factors were found to be missing in some models, and none of these models consider the HCI and usability when designing digital nudging. According to Issa and Isaias (2015), the aim of Human Computer Interaction (HCI) is to design a user interface ( UI) that meet users' needs and requirements. UI design aims at maximizing the usability and user experience (UX). The usability refers to the ease of use and efficiency. As mentioned above, there is no general way to design choices due to the changes in the environment and the ways in which humans interact with technologies (Mirsch et al., 2017; Weinmann et al., 2016). Digital nudging is an emergent concept that can potentially inspire HCI research (Mirsch et al., 2017). Furthermore, all the models assess the effectiveness of the digital nudging at the end of the entire process in the test phase. Evaluation is a critical 
step in developing new technology in order to ensure that the new technology meets the user's requirements (Issa \& Isaias, 2015). Furthermore, no digital nudging model appropriately identifies the environmental barriers as factors that affect the user's behavior. Although the environment is mentioned as a possible influencing factor, no details are given. Digital choice environments are included in the user interface. The ways in which a system is organized and presented in the digital environment is more likely to influence the user's decisions (Issa \& Isaias, 2015; Weinmann et al., 2016). This is central to the design of nudges. (Dimitrova, Mitrovic, Piotrkowicz, Lau, \& Weerasinghe, 2017). Therefore, it is important to understand the behavioral effects of interface design elements on the user's decisions, and to ensure that digital nudging is properly conducted and does not occur at random. Finally, ethics must be taken into account when designing a nudge. It is unethical to nudge people towards decisions that could harm them or compromise their welfare (Hortal, 2019). Also, it is important to not use individuals' behavioral barriers such as inertia or inattention against them (Sunstein, 2016).

\subsubsection{The Study Proposed Model}

The study proposed e-nudge model in the digital environment comprises three phases. The first phase involves analysing user behaviour which consists of two stages: planning and analysis. The second phase concerns nudging or designing user behaviour which also consists of two stages: design and implementation. The last phase is evaluating user behaviour which includes the testing stage. All three phases include a feedback loop to enhance the development process. The e-Nudging model architecture is illustrated in Figure1.

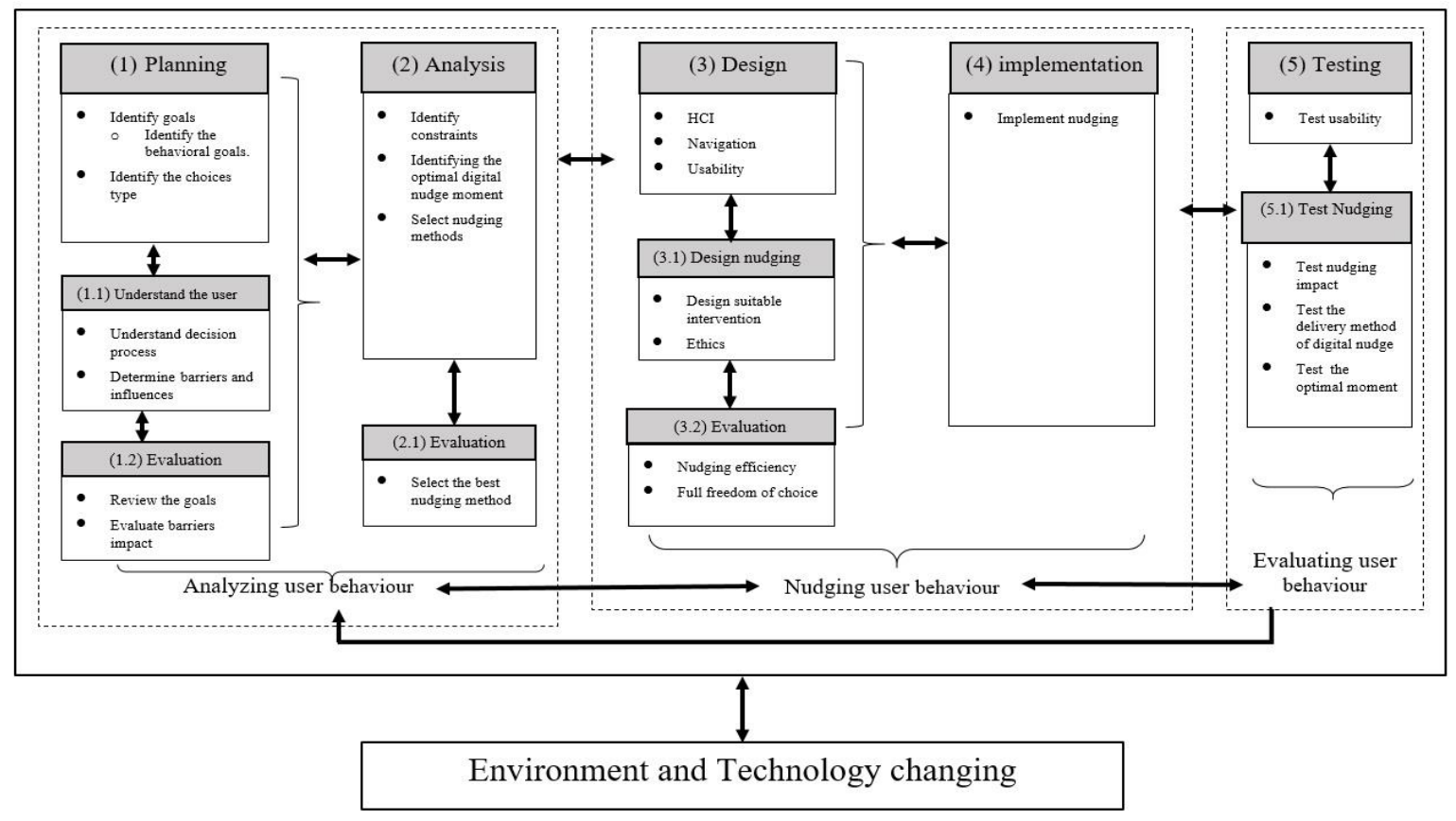

Figure 1. Proposed e-Nudging Model for higher education in KSA

However, in the education field, a few studies applied nudging in a digital environment. Dimitrova et al. (2017) applied personalized nudges to encourage students to engage with video content by rating and adding comments in an active video watching system (AVW). Smith, White, Kuzyk, and Tierney (2018) also designed a "grade nudge" sent to students via e-mail after each assignment. The findings indicated that the homework performance improved by about four percentage points. Andor et al. (2018) tested nudging as a prompt which was embedded in the course interface as a pop-up rather than an external website to reduce the drop-out rate in MOOCs. The nudging prompt increased the course completion rate by $19 \%$. This study did not apply to students, schools, or universities. 


\section{RESEARCH METHODOLOGY}

This study concerns the intersection of three streams: digital nudging, HCI and the education system. In fact, Information Systems (IS) researchers frequently face challenges in that research findings often do not provide enough explanations about a phenomenon of interest. Therefore, in this study, the mixed-methods research design can be used as a powerful tool that enables IS researchers to deal with such conditions and achieve a better understanding of the research problem (Venkatesh, Brown, \& Bala, 2013). The mixed-methods research approach can be defined as a procedure for collecting, analyzing, and integrating the findings from both quantitative and qualitative data within a single study (Doyle, Brady, \& Byrne, 2009; Johnson, Onwuegbuzie, \& Turner, 2007).

The study will apply an approach called "Explanatory Sequential Design" which is a type of mixed-methods research design in order to achieve research objectives and answer the research questions. The approach consists of two phases: a quantitative phase, followed by a qualitative phase. This means the data will be collected equally from each phase: quantitative data via online survey in order to obtain students' academics and technology staff's opinions, to identify any new factors that may influence the impact of the e-nudging model. In the next phase, the qualitative method will use semi-structured interviews to obtain expert academics' opinions about the use of the e-nudging model, and to obtain a better understanding of these constructed factors.

\section{CONCLUSION}

This study will contribute a new theoretical perspective to the growing literature on the relationship between HCI and digital nudging. The concept of digital nudging is likely to add a new aspect to UI and user experience (UX) design. A clear understanding of the behavioral and cognitive effects on the human decision-making process will assist UI designers to improve their design and determine whether or not the digital environment nudges the users as intended. Also, this study aims to provide academic knowledge about important behavioral, cognitive and environmental factors in the education field, facilitating the design of successful digital nudging in learning systems.

In the context of education in the KSA, this study will make a contribution in terms of practical application. Until recently, to the best of the researcher's knowledge, no study has been conducted on the initiation and assessment of the effectiveness of digital nudging in Saudi Arabian universities. This study aims to assess the proposed e-nudging model, the relevant factors and how they influence the effectiveness of digital nudging in a learning system. Given the Saudi Arabian government's vison for the development of the higher education sector, the research findings will assist stakeholders such as universities, education departments and governments to make more informed decisions about applying digital nudging successfully in the education system and reap the benefits of this emerging concept. The main outcome of this study will be an e-nudging model for higher education in the KSA. This model will provide the foundation for stakeholders to effectively establish and implement the e-nudging model in the Saudi education system. Moreover, this model can be applied in the Gulf Cooperation Council (GCC) countries as they share many common factors and characteristics such as culture, religion, social, languages, and economic and financial system.

Finally, the proposed model factors and relationships need to be empirically tested. In future work, this reserarch will extend by examining our e-nudge model using a mixed-methods approach to determine the factors that influence the effectiveness of the proposed e-nudging model for higher education in Saudi Arabia. At the end, this paper is portion of a large research project that the approach results and reserch findings will be published in future.

\section{REFERENCES}

Andor, M. A., Fels, K. M., Renz, J., \& Rzepka, S. (2018). Do planning prompts increase educational success? Evidence from randomized controlled trials in MOOCs: Ruhr Economic Papers.

Bertheim, J. (2018). Designing Digital Nudges to Encourage Sustainable Decisions: Developing and Testing a Framework. In.

Bettinger, E., \& Slonim, R. (2007). Patience among children. Journal of Public Economics, 91(1-2), 343-363. 
Bradbury, A., McGimpsey, I., \& Santori, D. (2013). Revising rationality: the use of 'Nudge'approaches in neoliberal education policy. Journal of Education Policy, 28(2), 247-267.

Bradford, P., Porciello, M., Balkon, N., \& Backus, D. (2007). The Blackboard learning system: The be all and end all in educational instruction? Journal of Educational Technology Systems, 35(3), 301-314.

Brock, T. (2010). Young adults and higher education: Barriers and breakthroughs to success. The future of children, 109-132.

Castleman, B. L., \& Meyer, K. (2016). Can text message nudges improve academic outcomes in college? Evidence from a west virginia initiative. Center for Education Policy and Workforce Competitiveness Working Paper, 43.

Damgaard, M. T., \& Nielsen, H. S. (2018). Nudging in education. Economics of Education Review, 64, 313-342.

Dimitrova, V., Mitrovic, A., Piotrkowicz, A., Lau, L., \& Weerasinghe, A. (2017). Using learning analytics to devise interactive personalised nudges for active video watching. Paper presented at the Proceedings of the 25th Conference on User Modeling, Adaptation and Personalization.

Doyle, L., Brady, A.-M., \& Byrne, G. (2009). An overview of mixed methods research. Journal of research in nursing, 14(2), 175-185.

Green, L., Fry, A. F., \& Myerson, J. (1994). Discounting of delayed rewards: A life-span comparison. Psychological science, $5(1), 33-36$

Hortal, A. (2019). Nudging and educating: bounded axiological rationality in behavioral insights. Behavioural Public Policy, 1-24.

Hovdhaugen, E., \& Aamodt, P. O. (2009). Learning environment: Relevant or not to students' decision to leave university? Quality in higher education, 15(2), 177-189.

Issa, T., \& Isaias, P. (2015). Color, Prototyping and Navigation, Principles and Guidelines Design, Evaluation and Testing; Task Analysis. In Sustainable Design (pp. 71-86): Springer.

Johnson, R. B., Onwuegbuzie, A. J., \& Turner, L. A. (2007). Toward a definition of mixed methods research. Journal of mixed methods research, 1(2), 112-133.

Khan, I. A. (2011). An analysis of learning barriers: The Saudi Arabian context. International Education Studies, 4(1), 242-247.

Landry, B. J., Griffeth, R., \& Hartman, S. (2006). Measuring student perceptions of blackboard using the technology acceptance model. Decision Sciences Journal of Innovative Education, 4(1), 87-99.

Ly, K., Mazar, N., Zhao, M., \& Soman, D. (2013). A practitioner's guide to nudging. Rotman School of Management Working Paper(2609347).

Meske, C., \& Potthoff, T. (2017). The DINU-model-a process model for the design of nudges.

Mirsch, T., Lehrer, C., \& Jung, R. (2017). Digital nudging: Altering user behavior in digital environments. Proceedings der 13. Internationalen Tagung Wirtschaftsinformatik (WI 2017), 634-648.

Patterson, R. W. (2018). Can behavioral tools improve online student outcomes? Experimental evidence from a massive open online course. Journal of Economic Behavior \& Organization, 153, 293-321.

Purohit, A. K., \& Holzer, A. (2019). Functional Digital Nudges: Identifying Optimal Timing for Effective Behavior Change. Paper presented at the Extended Abstracts of the 2019 CHI Conference on Human Factors in Computing Systems.

Schneider, C., Weinmann, M., \& vom Brocke, J. (2018). Digital Nudging-Influencing Choices by Using Interface Design. Communications of the ACM, 61(7), 67-73.

Smith, White, D., Kuzyk, P., \& Tierney, J. (2018). Improved grade outcomes with an e-mailed "grade nudge". The Journal of Economic Education, 49(1), 1-7.

Sulphey, M., \& Alkahtani, N. S. (2018). Academic excellences of business graduates through nudging: prospects in Saudi Arabia. International Journal of Innovation and Learning, 24(1), 98-114.

Sunstein, C. R. (2016). Do people like nudges. Admin. L. Rev., 68, 177.

Talebian, S., Mohammadi, H. M., \& Rezvanfar, A. (2014). Information and communication technology (ICT) in higher education: advantages, disadvantages, conveniences and limitations of applying e-learning to agricultural students in Iran. Procedia-Social and Behavioral Sciences, 152, 300-305.

Thaler, R. H., \& Sunstein, C. R. (2008). Nudge: Improving decisions about health, wealth, and happiness: Penguin.

Venkatesh, V., Brown, S. A., \& Bala, H. (2013). Bridging the qualitative-quantitative divide: Guidelines for conducting mixed methods research in information systems. MIS quarterly, 21-54.

Weinmann, M., Schneider, C., \& vom Brocke, J. (2016). Digital Nudging Business \& Information Systems Engineering, 58(6), 433-436.

Zhang, H., Almeroth, K., Knight, A., Bulger, M., \& Mayer, R. (2007). Moodog: Tracking students' online learning activities. Paper presented at the EdMedia+ Innovate Learning. 